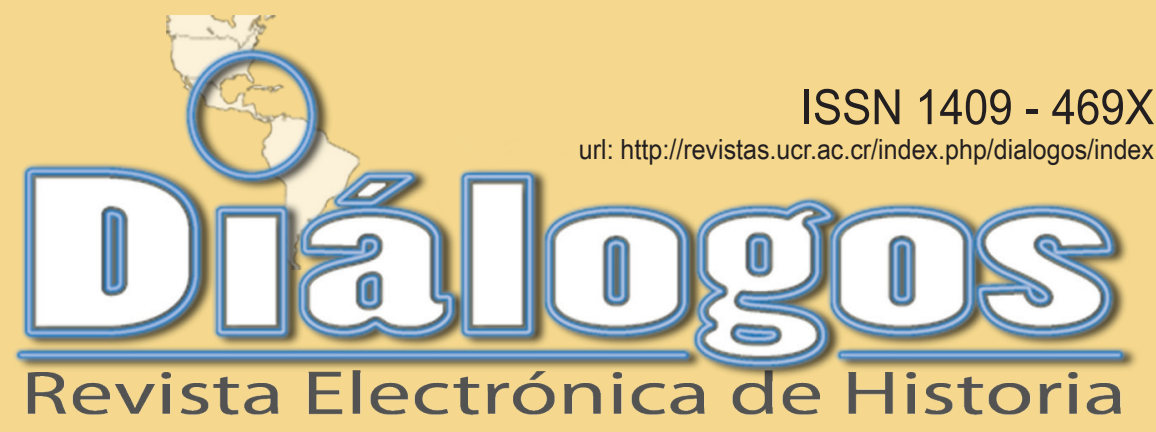

Escuela de Historia. Universidad de Costa Rica Volumen 15 Especial Región Occidente de Costa Rica - Octubre, 2014

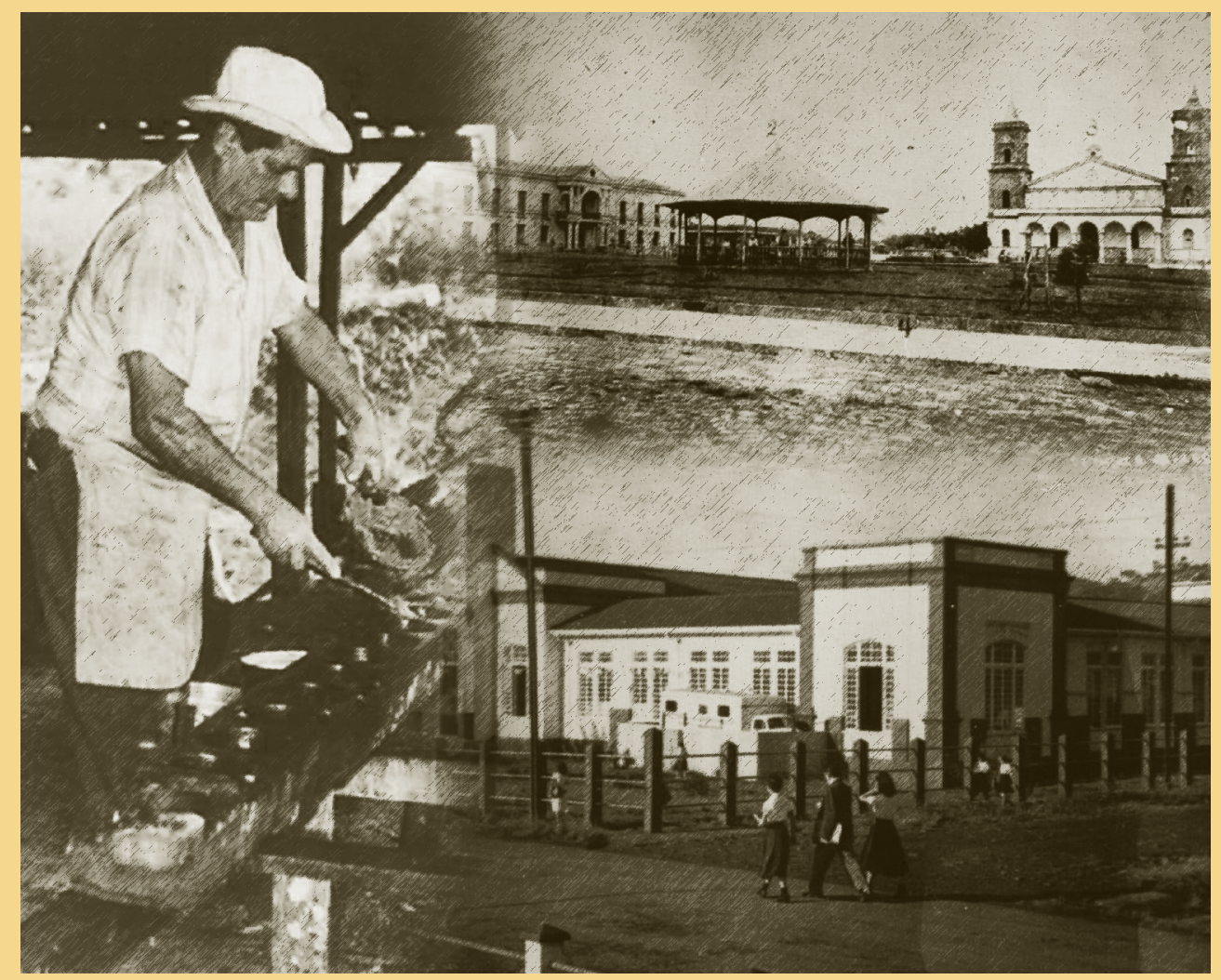

Director de la Revista: Dr. Juan José Marín Hernández juan.marinhernandez@ucr.ac.cr

Editor académico: Dr. David Díaz Arias - david.diaz@ucr.ac.cr Editor técnico: M.Sc. Marcela Quirós G. - marcela.quiros@ucr.ac.cr 
Dr. Juan José Marín Hernández, Catedrático. Director del Centro de Investigaciones Históricas de América Central. Universidad de Costa Rica. Costa Rica. juan. marin@ucr.ac.cr

Dr. David Díaz Arias: Catedrático. Historia Política, Director del posgrado de Historia y Docente de la Escuela de Historia, Universidad de Costa Rica, Costa Rica.david.diaz@ucr.ac.cr

Dr. Ronny Viales Hurtado. Catedrático. Historia Económica y Social. Universidad de Costa Rica. Director de la Escuela de Historia. Costa Rica. ronny. viales@ucr.ac.cr

MSc. Francisco Enríquez. Historia Social. Universidad de Costa Rica. Costa Rica. francisco.enriquez@ucr. ac.cr

Dra. Ana María Botey. Historia de los movimientos sociales. Universidad de Costa Rica. Costa Rica. abotey@gmail.com

\section{Miembros del Consejo Asesor Internacional:}

Dr. José Cal Montoya. Universidad de San Carlos de Guatemala. Guatemala. jecalm@correo.url.edu.gt

Dr. Juan Manuel Palacio. Universidad Nacional de San Martín. Argentina.jpalacio@unsam.edu.ar

Dr. Eduardo Rey. Universidad de Santiago de Compostela. España. ereyt@usc.es

Dr. Heriberto Cairo Carou. Departamento de Ciencia Política y de la Administración III - Universidad Complutense de Madrid. España. hcairoca@cps.ucm.es

Dra. Rosa de la Fuente. Departamento de Ciencia Política y de la Administración III Universidad Complutense de Madrid. España. rdelafuente@cps. ucm.es

Dr. Javier Franzé. Departamento de Ciencia Política y de la Administración III Universidad Complutense de Madrid. España. javier.franze@cps.ucm.es

Dr. Jaime Preciado Coronado Departamento de Estudios Ibéricos y Latinoamericanos. Universidad de Guadalajara. México.japreco@hotmail.com

Dr. Gerónimo de Sierra. Vicerrector de la Universidade Federal da Integração Latino-Americana (UNILA) y Departamento de Sociología, Facultad de Ciencias

Sociales de la Universidad de la República. Uruguay. geronimo@fcs.edu.uy

Dr. Antonio Palazuelos. Departamento de Ciencia Política y de la Administración III - Universidad Complutense de Madrid. España. palazuelosa@cps. ucm.es

Dr. Werner Mackenbach. Universidad Potsdam. Alemania.werner.mackenbach@uni-potsdam.de

Dr. Guillermo Castro. Ciudad del Saber Panamá. Panamá.gcastro@cdspanama.org

Dra. Natalia Milanesio. University of Houston. Estados Unidos.nmilane2@Central.UH.EDU

Dr. Ricardo González Leandri. Consejo Superior de Investigaciones Científicas - España. España. rgleandri@gmail.com

Dra. Mayra Espina. Centro de Estudios Psicológicos y Sociológicos, La Habana. Cuba.mjdcips@ceniai.inf.cu

Dra. Montserrat Llonch. Departamento de Economía e Historia Económica Universidad Autónoma de Barcelona. España. montserrat.llonch@uab.es

Dra. Estela Grassi. Universidad de Buenos Aires. Argentina. estelagrassi@gmail.com

Dra. Yolanda Blasco. Universidad de Barcelona. España. yolandablasco@ub.edu

Dr. Alfredo Falero. Departamento de Sociología. Universidad de la República. Uruguay. alfredof@adinet. com.uy

Portada:

Fotografía: ( Collage "Campesinos en la producción de dulce en un trapiche de Rincón de Mora, Ran Ramón, 1987" ; "Panorámica del Antiguo Palacio Municipal, Antigua Iglesia, Parque y Kiosco de San Ramón, hacia 1920; y Escuela Jorge Washinton, San Ramón hacia 1955). Estas fotografías pertenecen a la Colección Fotográfica del Museo Regional de San Ramón- UCR. Montaje fotográfico: Lic. Juan Gabriel Madrigal Cubero ).

\section{Equipo Técnico Editorial:}

Diagramación y

Edición técnica:

M.Sc. Marcela Quirós Garita. marcela.quiros@ucr.ac.cr

Soporte técnico: Kevin Trejos Vargas

Revisión filológica: Baruc Chavarría Castro 
"Diálogos Revista Electrónica de Historia" se publica desde octubre de 1999.

\section{Diálogos está en los siguientes repositorios:}

Dialnet

http://dialnet.unirioja.es/servlet/

revista?tipo_busqueda=CODIGO\&clave_revista $=3325$

\section{Latindex}

http://www.latindex.unam.mx/larga.php?opcion=1\&folio=12995;

\section{UCRindex}

http://www.revistas.ucr.ac.cr

\section{Scielo}

http://www.scielo.cll

\section{eRevistas}

http://www.erevistas.csic.es/

\section{REDALYC}

http://redalyc.uaemex.mx/src/inicio/FrmBusRevs2.jsp?iEdoRev=2\&cvepai=11;

\section{LANIC}

http://lanic.utexas.edu/la/ca/cr/indexesp.html;

Repositorio de Revistas Universidad de Costa Rica

http://www.latindex.ucr.ac.cr/

Directorio y recolector de recursos digitales del

Ministerio de Cultura de España

http://roai.mcu.es/es/inicio/inicio.cmo

DOAJ Directory of open access \& Hybrid journals

http://www.doaj.org/doaj?func=byTitle\&hybrid=1\&query=D

Biblioteca de Georgetown

http://library.georgetown.edu/newjour/d/msg02735.htm

Asociación para el Fomento de los Estudios Históricos en Centroamérica

http://afehc.apinc.org/index.php?action=fi_aff\&id=1774

Universidad de Saskatchewan, Canadá

https://library.usask.ca/ejournals/view/1000000000397982

Monografias

http://www.monografias.com/Links/Historia/more12.shtml

\section{Hispanianova}

http://hispanianova.rediris.es/general/enlaces/hn0708.htm

Universidad del Norte, Colombia

http://www.uninorte.edu.co/publicaciones/memorias/enlaces.htm

Universidad Autónoma de Barcelona

http://seneca.uab.es/historia/hn0708.htm

Repositorio Invenia - Gestión del Conocimiento http://www.invenia.es/oai:dialnet.unirioja.es:ART0000086144

\section{Enlace Académico}

http://www.enlaceacademico.org/biblioteca/

revistas-en-formato-digital-centroamerica/

\section{Electronic Resources}

http://sunzi1.lib.hku.hk/ER/detail/hkul/3987318

Revistas académicas en texto completo http://web.prw.net/ vtorres/

Diálogos se anuncia en las siguientes instituciones y sitios académicos:

Maestroteca

http://www.maestroteca.com/detail/553/dialogos-revista-electronica-de-historia.html

Biblioteca de Georgetown

http://library.georgetown.edu/newjour/d/msg02735.htm

Asociación para el Fomento de los Estudios Históricos en Centroamérica

http://afehc.apinc.org/index.php?action=fi_aff\&id=1774

Universidad de Saskatchewan, Canadá

https://library.usask.ca/ejournals/view/1000000000397982

Monografias

http://www.monografias.com/Links/Historia/more12.shtm

Hispanianova

http://hispanianova.rediris.es/general/enlaces/hn0708.htm

Universidad del Norte, Colombia

http://www.uninorte.edu.co/publicaciones/memorias/enlaces.html

Universidad Autónoma de Barcelona

http://seneca.uab.es/historia/hn0708.htm

Repositorio Invenia - Gestión del Conocimiento

http://www.invenia.es/oai:dialnet.unirioja.es:ART0000086144

Enlace Académico

http://www.enlaceacademico.org/biblioteca/

revistas-en-formato-digital-centroamerical

\section{Electronic Resources}

http://sunzi1.lib.hku.hk/ER/detail/hkul/3987318

Revistas académicas en texto completo http://web.prw.net/ vtorres/

Diálogos Revista de Historia está catalogada por Sherpa Romeo como una revista verde.

La revista electrónica Diálogos es financiada por Vicerrectoría de Investigación de la Universidad de Costa Rica

Citado en: Scielo Dialnet - eRevistas - UCRindex Latindex - REDALYC - DOAJDirectorio y recolector de recursos digitales del Ministerio de Cultura de España

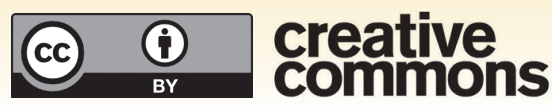




\title{
LOS BOYEROS EN EL NOROCCIDENTE DEL VALLE CENTRAL DE COSTA RICA ENTRE LOS SIGLOS XIX Y XX
}

\section{THE OXCART MEN IN THE NORTH-WEST CENTRAL REGION OF THE CENTRAL VALLEY OF COSTA RICA AMONG THE CENTURIES XIX AND XX}

\author{
Javier Rodríguez Sancho
}

\begin{abstract}
Palabras claves
Boyeros, medio de transporte, economía rural, pobreza y noroccidente del Valle Central.

\section{Keywords}

Oxcart men, means of transportation, rural economy, poverty and North-West Central Region.
\end{abstract}

Fecha de recepción: 7 de febrero, 2014 - Fecha de aceptación: 1 de junio, 2014

\section{Resumen}

En este artículo, se interpreta un fragmento de la historia "nacional" delineada por un oficio en torno a los transportes que estuvo matizado por varios aspectos de la vida rural de los siglos XIX y XX. La denominada sección noroccidental del Valle Central de Costa Rica, que comprende los actuales cantones de San Ramón, Palmares, Naranjo, Grecia, Valverde Vega, Poás, Atenas y Zarcero fue acoplada paulatinamente a la economía "nacional" con el soporte de un oficio como el "boyeo". La región se convirtió en uno de los escenarios de los boyeros, quienes ofrecieron sus servicios de acarreo, un recurso complementario de la economía rural.

\begin{abstract}
This article analyzes a piece of national history related to Costa Rican rural means of transportation in the XIX and XX centuries. Particulary, the study focuses on the North-West Central Region of this country that groups the cantons of San Ramón, Palmares, Naranjo, Grecia, Valverde Vega, Poás, Atenas y Zarcero, where the "boyero" helped develop the rural economy by offering their transport services from town to town.
\end{abstract}




\section{LOS BOYEROS EN EL NOROCCIDENTE DEL VALLE CENTRAL DE COSTA RICA ENTRE LOS SIGLOS XIX Y XX}

\section{INTRODUCCIÓN}

Pese a que en las últimas décadas del siglo XX el boyero y la carreta fueron representados dentro del imaginario costarricense como elementos del folclor, el oficio del boyeo como tal ha sido abordado tímidamente por la historiografía. Además, un enfoque empleado por los medios de comunicación estereotipó la actividad entre lo turístico y lo comercial, desfavoreciendo la interpretación de los orígenes, la evolución y el declive histórico. Sin embargo, el oficio alberga importantes componentes de la historia costarricense que merecen atención académica, pero distanciándose del tratamiento tradicional de la denominada cultura oficial, que reforzó un romanticismo de insuficiente perfil interpretativo.

Entre algunos escritores costarricenses, ya fueran poetas, cuentistas o periodistas, se operó un proceso de fragua en derredor de una imagen del boyero, que rondaría por la de una persona pobre y de escasos cuestionamientos sociales. Una forma de visualización que esquivó el comprenderlo dentro de un tipo de capitalismo rural, uno de los vehículos de la oligarquía cafetalera. Con fundamento en esta complejidad histórica, se hará girar un eje de discusión, tratando de entender al boyero como un sujeto histórico. El esclarecimiento de sus dificultades tiene implícito una serie de mecanismos que desnudarían la estructura productiva y comercial del país (Zeledón, 2010; Dobles, C., Murillo, C. y Chang, G., 2008).

Actualmente, sería simple de reconocer que el poeta Julián Marchena (18971988) lidió con un tema que, poco a poco, se perfilaría con un carácter nacional. En el libro Alas en fuga de 1941, así se refleja y en una de sus composiciones se evocaba místicamente al medio de transporte, a saber, en el Romance de las carretas, que en secundaria miles de jóvenes leyeron como parte del Programa de Español. Entre tanto, los académicos Constantino Láscaris y Guillermo Malavassi puntualizaron un concepto que no debe pasar por alto en la explicación, ya que: "Romancear es un poetizar que linda entre lo lírico y lo épico. Romancear es idealizar" (1975, p. 101). Esto manifiesta una de las vetas tratadas por la literatura, que los grupos de poder vallecentralino manosearon en favor de un imaginario nacional. En las líneas del poema, se apuesta a situaciones quiméricas que se distanciarían de los sudores de los boyeros de carne y hueso. En una estrofa se enuncia lo siguiente: 


$$
\begin{gathered}
\text { Cuando el día ya no es día } \\
\text { y la noche aún no llega, } \\
\text { — perfiles desdibujados, } \\
\text { cielo azul de luces trémulas- } \\
\text { por las rutas del ensueño } \\
\text { van rodando las carretas. }
\end{gathered}
$$

Además, es importante apuntar que en varios cantones del área metropolitana como en Escazú, se celebra en marzo de cada año el Día del boyero. En una festividad de fin de año, la ciudad capital organiza un singular desfile (Díaz, 2006, p. 24 A). En Alajuelita, Desamparados, Coronado y Aserrí, se les festeja, lo que acicalaría una mirada melancólica del pasado rural. Las provincias de Guanacaste, Heredia, Cartago y Alajuela asumieron los ritos propios de un recuerdo colectivo en torno al boyero como un ser idílico, que los monumentos, las placas y los desfiles de las distintas organizaciones reproducen por doquier. Así, se refuerza el antecedente sobre la existencia de un sinnúmero de fundaciones, asociaciones y comités que rinden pleitesía al boyero y a la carreta.

En un breve recuento de festividades en el noroccidente del Valle Central, se sabe que en la parroquia de San Ramón Nonato se realiza un desfile durante las fiestas patronales; un ejemplo de ello lo resaltaba la revista Entre Cantones (2009, pp. 16-19), que constató la participación de más de doscientas carretas en agosto de 2009. A escasos kilómetros de distancia, el distrito de Zaragoza en Palmares lo ha efectuado en las fiestas del Pilar, así como Sabana Larga de Atenas, Zarcero y San Pedro de Poás. El cantón de Valverde Vega en las celebraciones de Santiago Apóstol efectuaba un desfile en julio y el distrito de San Isidro de Grecia consumaba un evento parecido en mayo. Pese a lo referido, surge una interrogante que brota alrededor de las intenciones de fondo, que procurarían despertar un sentimiento colectivo de un pasado campesino esplendoroso y recuperable en las celebraciones actuales; al menos, esta sería una de las pretensiones desde el presente.

No obstante, en el presente, se estima que al morir el boyero perecerá una expresión de la vida rural, que también produjo una variante lingüística: “... profundamente insertado en la cotidianidad de un vasto número de familias" (2009, pp. 115), tal como lo admite la antropóloga lingüista Giselle Chang Vargas. El oficio referido dinamizó los transportes y la economía regional en el decurso de dos centurias (Dobles, C., Murillo, C. y Chang, G., 2008). Cabe adicionar que a comienzos del siglo XX, Manuel González - conocido como Magón - en su relato La propia, publicado en 1910, figuraba un aspecto del doble sentido popular y del erotismo en el refrán: "Al güey viejo le gusta el cojollo tierno". Al relato se le acredita el formar parte de una ruptura literaria mantenida 
por sus predecesores ante el idilio campesino. En esto subyacen ciertas razones de orden moral, pero sobre todo las económicas que se asociarían con las penurias del campesino, un hombre con limitado acceso a los bienes materiales, a la educación formal, etcétera.

Las leyendas populares también circundaron una vertiente referida al boyero, a la carreta y a los bueyes. Por décadas, La carreta sin bueyes fue vox populi ${ }^{1} \mathrm{y}$ pudo esparcir miedo o al menos cierta curiosidad entre los antepasados, aunque a finales del siglo XX ya era poco conocida entre la niñez y la juventud. El romance de Aquileo Echeverría, Un hermano, retomaba la leyenda para referenciar un universo imaginario con asidero en la cotidianidad; según el texto, una carreta en marcha llevaba un ataúd con el infortunado Chico Serdas [sic], quien había dejado pendientes: algunas promesas sin saldar en el mundo de los mortales. Del mismo modo, Las concherías de 1905 dieron pie para referenciar a tipos mitologizados, al ambiente complejo y a las costumbres que evocarían algunos elementos de la estereotipada alma nacional. Con Las concherías de Echeverría, se cree que: “... [se] funda un tipo, el concho y en él, se dice, se reconoce el ser costarricense" (Rojas y Ovares, 1995, p. 36), que podría pensarse como un referente del boyero, un sujeto rústico del mundo rural.

En las zonas rurales, una sentencia popular con un sesgo moralizante delataba un rito etílico, a saber, montarse en la carreta, una realidad cotidiana que el ingenio popular parodió con creces. Entre los antepasados, no se podía pecar de ignorancia durante la faena diaria, ya que subirse al medio de transporte era sinónimo de cierta incapacidad para maniobrarlo, lo que podía llevar a un accidente de consideración en el camino, un aspecto que derivaba de una vieja legislación del siglo XIX. Según las referencias del decreto número 111 del 25 de enero de 1867, rubricado por José María Castro, se derogaron unos mandatos del número 9 del 20 de noviembre de 1854, en razón de considerárseles: demasiado rigurosos (Fernández, 1972). Es probable que los boyeros no estuvieran anuentes a respetar las leyes estatales que ponían en entredicho uno de los goces de la vida. Lo cierto era que las leyes los constreñían a no saborear del guaro de contrabando producido y comercializado a la vera de los caminos en las distintas rutas del territorio nacional, un formalismo poco creíble entre las formas de socialización y de consumo de los campesinos.

\section{UN ANTECEDENTE REMOTO DE LA CARRETA}

En el período colonial entre los siglos XVI y principios del XIX en la provincia más alejada de la Capitanía General de Guatemala, es decir, en Costa Rica, la carreta de bueyes no se utilizó, dado que los caminos carecían de las condiciones mínimas. 
La mula fue el medio privilegiado para ese período; en todo caso, la provincia de Costa Rica no poseía importancia económica para la administración colonial concentrada en el desarrollo del norte de Centroamérica. En las valoraciones de la historiadora Carolyn Hall, la provincia de Costa Rica no tuvo una red de caminos adecuados para carruajes de mayor calado como la carreta de bueyes. El territorio ocupado en ese momento estuvo surcado por un camino de mulas denominado como Camino Real, abierto en 1601, que desde la frontera noroeste con Nicaragua atravesaba por los poblados de Liberia, Bagaces, Cañas, Las Juntas (Zeledón, 2010), Esparza, entre otros, para adentrarse en la Meseta Central, asiento de importantes comerciantes, especuladores, curas y de los representantes del poder políticoadministrativo (Hall, 1991).

De acuerdo con el testimonio del irlandés Thomas Francis Meagher, quien estuvo en Costa Rica en 1858 - entre otros viajeros - , recogido en la Antología de viajeros del historiador costarricense Ricardo Fernández Guardia ${ }^{2}$, se refleja la impresión que le había suscitado un medio de transporte en la comarca de Esparza, a pocos kilómetros del puerto de Puntarenas. En un lugar de sesteo, prestó atención a lo que describe con las siguientes palabras: "Atravesando la plaza desmontamos en el portón de un patio en que había una muchedumbre de mulas, de carretas de café, de bueyes, de perros y carreteros" (Meagher, 1972, p. 352). No obstante, en las líneas precedentes de esa crónica se detallaban los componentes de la armazón del carruaje, un poco diferente de la carreta actual: "Son vehículos toscos. Un timón sale de un bastidor cuadrilongo, debajo del cual hay un eje ampernado. Las extremidades del eje sobresalen por entre discos o ruedas de cedro sólidas de cuatro a cinco pies de diámetro" (Meagher, 1972, p. 349).

También, es atinado mencionar que en los procesos de construcción de los templos parroquiales de Grecia y Palmares, desde finales del siglo XIX hasta la década de 1910, o el de San Ramón Nonato, posterior al terremoto del 4 de marzo de 1924 y en la década de 1930, se requirió del traslado de las estructuras de hierro, del cemento, de los vitrales y de las imágenes religiosas con el apoyo de los boyeros locales (Sanou, 2001, pp. 164-252). Algo similar sobrevino en Zarcero y Poás. En el caso de Naranjo, el referido terremoto de 1924 causó estragos que el cura de esa parroquia, José Del Olmo, pudo documentar con detalle en un informe al obispo de la diócesis de Alajuela (Del Olmo, 1929).

En varios de los distritos de los cantones referidos, se construyeron ermitas por iniciativa de los lugareños con el apoyo del boyero criollo, un patrón seguido en Zaragoza de Palmares. Por ejemplo, la construcción del Santuario del Pilar entre 1922 y 1925, sin dejar de mencionar la querella que se ventiló ante una comisión especial en el Vaticano (Roma) en 1905, por encargo del arzobispo de Costa Rica, 
Juan Gaspar Stork (Archivo de la Curia Metropolitana, 1906). Los zaragozanos litigaban contra su propio párroco, Manuel Bernardo Gómez, por unos legados o fondos que existían desde el siglo XIX en favor de la Pilarica, pero el señor cura intentaba utilizarlos en la construcción del templo principal de La Merced. Este revés fue pasajero, aunque puso en la picota el poderío infranqueable de Gómez, quien a fin de cuentas no consintió la iniciativa del poblado durante su curato, concluido en 1920. A pesar de ello, se admite que el altercado ayudaría a configurar una identidad local, coronada con el estreno del Santuario del Pilar y el inicio de las fiestas patronales el propio 12 de octubre de 1925, cuando la parroquia contaba con otro sacerdote, lejano a las rencillas del pasado (Junta Edificadora de Zaragoza, 1921; Parroquia de La Merced, 1925; Rodríguez, 2007). A propósito de fenómenos como el descrito, José Aurelio Sandí analizó el papel jugado por la Iglesia católica en el control del espacio y en la creación de un tipo de sociabilidad en varias parroquias de Costa Rica entre 1850 y 1920 (Sandí, 2011). Un pormenor detallado por Sandí se remonta a 1855 (Archivo Nacional de Costa Rica, 1855); en particular, los vecinos de San Ramón de los Palmares hicieron un esfuerzo compartido con el beneplácito del donador del terreno para levantar una ermita de barro, paja y madera en su propia parroquia, constituida un año antes, y de esta forma la administración eclesiástica extendía su influencia en las villas más recónditas.

\section{EL “GRANO DE ORO” EN EL SIGLO XIX}

Como antecedente histórico ineludible, la comercialización del café en la primera mitad del siglo XIX propició las condiciones para que surgiera un estrato de acarreadores permanentes u ocasionales. Se debe aclarar que también transportaban personas y por supuesto café en pergamino hacia Puntarenas, por caminos polvorientos en trayectos que podían demorar semanas desde la capital. Para la estación seca en la vertiente del Pacífico, que brindaba mejores condiciones climáticas, operaron los trasiegos, pero durante las lluvias entre mayo y noviembre los caminos eran un verdadero caos que la tracción animal sufría con creces, lo que disminuía el trasiego por razones obvias.

No obstante, la vía ferroviaria al Caribe costarricense, que en 1890 ya estaba habilitada, provocó que la actividad por Puntarenas perdiera una parte del trasiego acostumbrado. Los mercados europeos eran más accesibles y menos costosos por Limón (Murillo, 1995). Con lo dicho, no se pretende asegurar que Puntarenas quedara suplantado por completo, pues allí también operó un ferrocarril que les reimprimía vigor a las actividades comerciales con precios competitivos durante la 
primera mitad del siglo XX. En esa lógica, la sección noroccidental del Valle Central compuesta por ocho de los quince cantones actuales de la provincia de Alajuela, a saber, San Ramón, Palmares, Atenas, Zarcero, Naranjo, Valverde Vega, Poás y Grecia continuó vinculada a Puntarenas, tal como lo destaca el historiador Herbert Ulloa (1997, pp. 127-140), una situación que no se desligó de la realidad geográfica.

El mapa anterior luce un panorama territorial de la década de 1880. Los

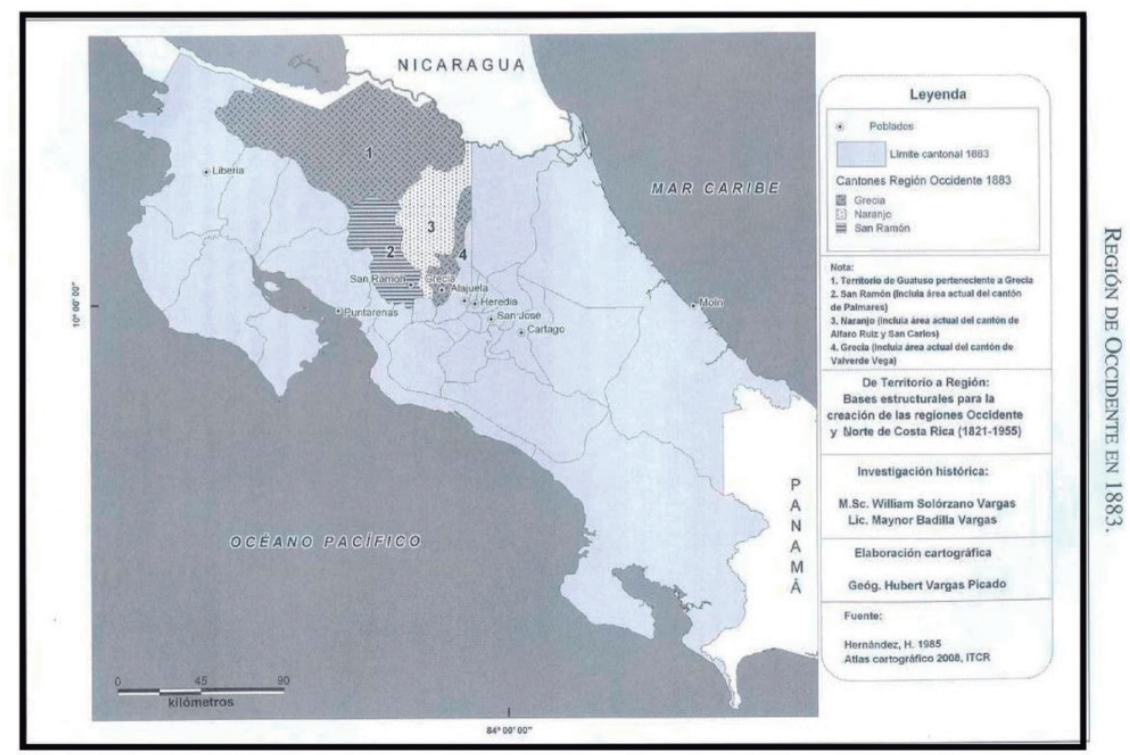

Figura 1. Región de Occidente en 1883.

Fuente: Badilla, M. y Solórzano, W. (2010). De territorio a región. Bases estructurales para la creación de las regiones Occidente y Norte de Costa Rica: 1821-1955. Costa Rica: Sociedad Editora Alquimia 2000, p. 28.

casos de Grecia y Naranjo fueron particulares, dado que en sus confines poseyeron límites con la República de Nicaragua. Aunque se aclara que en 1915 Naranjo ya no contaba con ese privilegio al haberse creado el cantón de Zarcero, que le cercenó una porción importante, al igual que San Carlos, cantón desde 1911; no obstante, el territorio de Guatuso siguió bajo el mandato de San Jerónimo de Grecia, tal como lo estudiaron los historiadores Maynor Badilla y William Solórzano.

De acuerdo con las apreciaciones de Carlos Abarca, hubo un complejo proceso político-administrativo en las decisiones de la Asamblea Legislativa en materia territorial que envolvió directamente al noroccidente del Valle Central. Sin perder de vista los factores productivo y comercial, la visión de los propietarios, de los acaparadores de la tierra y el asunto de los localismos, entre otras razones, que 
generaron los cambios en la cartografía de finales del siglo XIX y en los comienzos del XX. Por consiguiente, Abarca no duda en revalidar lo siguiente:

En 1882 se segregó a Grecia los territorios de San Carlos y Zarcero... En 1911 restó a Zarcero el área de San Carlos. En 1915 segregó de Naranjo, el territorio que dio origen al cantón de Zarcero. Sarapiquí, los Chiles, Upala y Guatuso - territorios de Grecia - quedaron ligeramente vinculados a San Carlos. (Abarca, 2011, p. 24)

Conforme se vinculaba la economía nacional al engranaje capitalista mundial, similar a lo sucedido en Guatemala, El Salvador u otros países de las regiones tropicales, las elites económicas promovieron proyectos en materia de caminos diseñados para controlar el mercado local, según lo reconoce el historiador Mario Samper $(1995,1998)$. Entre 1844 y 1846, la Sociedad Económica Itinerante, compuesta por varios cafetaleros u hombres de negocios vinculados con el poder político costarricense (Ulloa, 1997, pp. 30-31), impulsó una sustantiva mejora de los caminos carreteros, lo que les redituó con creces. La denominada Carretera Nacional enlazó aldeas, pueblos y centros urbanos e iba a suplantar a las mulas, un resabio del periodo colonial.

En Costa Rica hacia 1857, cuando concluyó la guerra contra los filibusteros de Walker, se creía que transitaban unas diez mil carretas, según una fuente del Ministerio de Obras Públicas y Transportes (1984). Sin embargo, la cifra puede verse como elevada para la época y no se ha encontrado una fuente de archivo que la corrobore en la actualidad. A pesar de lo cual la poderosa Sociedad Económica de Guatemala (1848), juzgaba que había unas dos mil carretas en el territorio costarricense, casi una década antes.

Es significativo señalar que en las postrimerías del siglo XIX hubo una fábrica de carretas en San Ramón, propiedad de "ñor" Fructuoso Barrantes; en Sarchí Sur, Fructuoso Chaverri tuvo otra, pero regentada por Joaquín Chaverri, de acuerdo a Constantino Láscaris y Guillermo Malavassi (1975, pp. 42-50). Sin dejar de referir que en el cantón de San Mateo, aledaño a la sección noroccidental del Valle Central y paso en la ruta hacia Puntarenas, hubo un auge en la producción de ese medio de transporte. Además, se tienen referencias de antiguas fábricas en La Uruca, Desamparados, Escazú y Tejar. En Puriscal, Zapote y Cartago se registraron talleres de un conjunto mayor de localidades a lo largo del país. En la provincia de Guanacaste, la carreta artesanal se construía en cantones como Santa Cruz, Liberia, Filadelfia, Cañas u otros y se aprovechó como medio de acarreo más eficiente que su "hermana" de antaño, la cureña (Rodríguez, 1997, p. 44). 


\section{LOS LAZOS HISTÓRICOS DE UNA REGIÓN}

Los cantones que se ubican al noroccidente de la ciudad de Alajuela, la segunda en importancia del país, mantuvieron vínculos comerciales, productivos, políticos, además de los socioculturales, que estudios como los de Castro Sánchez y Willlink, Torres Rodríguez, Abarca Vásquez, Badilla Vargas y Solórzano Vargas ${ }^{4}$, entre otros, los comprueban. Posiblemente, algunas de las diferencias responden a cuestiones coyunturales ${ }^{5}$. En la actualidad, se puede reconocer que con Puntarenas hubo un vínculo, donde el cantón de Atenas funcionó como centro de acopio de las mercancías y del tráfico humano. Esta localidad anterior a la década de 1970 fue un punto de encuentro, debido a la estación del tren número 19 (ver Figura 2) en el distrito de Concepción, caserío de Río Grande ${ }^{6}$, que originó un microuniverso social de relevancia para San Ramón y Palmares ${ }^{7}$. En la primera mitad del siglo XX, la producción cafetalera de un sector de la región noroccidental se transportó hacia Río Grande (Ulloa, 1997); entre tanto, las mercancías que abastecieron las plazas locales llegaron por la misma ruta, lo que propició varios sesteos para acampar. La Figura 2 deja ver el tráfico de carretas en 1922:

Los cantones de Atenas, Palmares y San Ramón tuvieron un pasado compartido que tardó décadas en forjarse, para luego quedar resquebrajado, a partir de obras

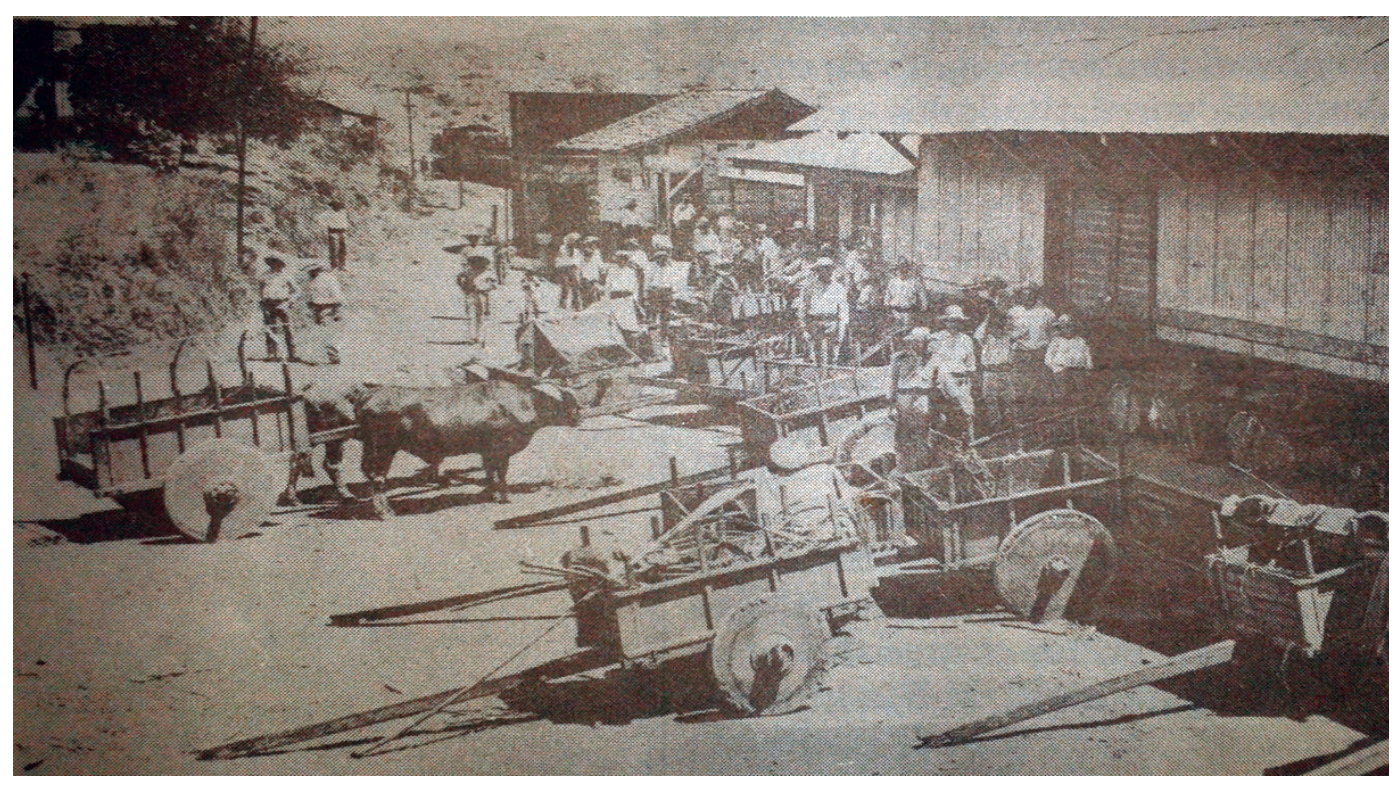

Figura 2. Estación del tren $\mathrm{N}^{\circ}$ 19, Río Grande de Atenas, 1922.

Fuente: Álbum de Manuel Gómez Miralles. En: (Samper, 1992, p. 48). 
como la autopista Bernardo Soto, inaugurada en diciembre de 1972. Sin perder de vista que en la década de 1940 la carretera Panamericana ya era una arteria estratégica en el corazón de la región. No obstante, se cree que en el decenio de 1970 Atenas comenzó a separarse de un vínculo histórico con sus dos vecinos, en virtud de los nuevos entronques viales que favorecían otras rutas y prioridades económicas de los grupos de poder nacional. Por consiguiente, San Ramón, Palmares, Naranjo y Grecia quedaron atravesados por la carretera Bernardo Soto, mientras que Sarchí tuvo salida por Naranjo o Grecia, a pocos kilómetros de distancia, y San Pedro, en las faldas del volcán Poás, a través de Grecia, un centro poblacional a unos 30 kilómetros de la ciudad de San José.

Ante lo dicho, se debe adicionar un elemento coyuntural, dado que el alto precio del café restaba importancia a los cultivos de subsistencia, por un producto de exportación que, dicho sea de paso, era bastante sensible en ciertas situaciones derivadas de las transacciones en las bolsas de Londres o Nueva York. Las fluctuaciones del mercado, en ocasiones, tiraron por el suelo la bonanza del monocultivo, al igual que en Guatemala o en El Salvador. Sin embargo, en ese momento, el café fue visto como el grano de oro, que deslumbró a los caficultores del noroccidente del Valle Central con sus consecuentes problemas sociales, que la década de 1980 manifestaría (Abarca, 1999; Rodríguez, 2008, 2012).

\section{LAS PARADOJAS DEL CAMPO}

A efectos de comprender un fenómeno ligado a la producción, a la comercialización y al transporte en la región de estudio, se utilizan datos de los Censos de Población de 1973 y 1984. También, las estadísticas agropecuarias de 1950 y 1984 son válidas para hallar pautas que contribuyan a explicar la evolución de los cantones del noroccidente durante la segunda mitad del siglo XX. Por tanto, la interpretación de los cambios y de las continuidades es un referente clave de este subapartado.

Ahora bien, según el Censo de Población de 1973, la Población Económicamente Activa (PEA) agrícola bajó a un 36,4\%, cuando en la década de 1950 representaba más de la mitad. No obstante, en 1975, un 65\% de la población centroamericana vivía en las zonas rurales, tal como lo afirmaban Héctor Pérez y Yolanda Baires (1987, p. 85). En ese momento, se impulsaba un Estado de corte empresarial que no lograría sus objetivos al final de la década, para mostrar otro rostro en medio de una población que rondaba el millón ochocientos mil habitantes. Tampoco se debe soslayar que al comienzo de la década de 1970 el Mercado Común ya había sucumbido de la mano de una desarticulación del modelo de sustitución 
de las importaciones, referido como de desarrollo hacia adentro e impulsado este por la Comisión Económica para América Latina, CEPAL. Los saldos negativos, según el caso de cada país centroamericano, se evidenciaron en una pobreza cada vez mayor en contraposición al enriquecimiento de las cámaras empresariales.

Aunque se debe aceptar que la caficultura generó un desarrollo visible en la economía costarricense, sería un error de análisis pensar que era el único dinamizador productivo. Por ejemplo, los cantones de Grecia y Poás tuvieron un desarrollo significativo con el cultivo de la caña de azúcar desde la década de 1930 (Anuario General de Costa Rica, 1934). En San Ramón, la ganadería contribuyó con lo suyo, tal como lo sostienen Silvia Castro y Frank Willink (1989). Mientras, Zarcero gozó de una conquista más clara con dicha actividad, especializándose en la producción lechera, sin abandonar la siembra de hortalizas y vegetales.

En Palmares, el cultivo de tabaco propició un auge en el decenio de 1920, que se prolongó hasta 1970, con una relativa bonanza de acuerdo con Carlos Abarca Vásquez (1999). Sin dejar de mencionar las siembras clandestinas que desde el siglo XIX fueron un dolor de cabeza para las autoridades, un asunto explicado por Yamileth González y María Pérez (1995). A más de mil metros sobre el nivel del mar, los cantones de Naranjo, Sarchí, Poás y Palmares fueron productores de café en la segunda mitad del siglo XX. En el presente, es la segunda región productora, solo superada por la Zona de los Santos (Instituto Costarricense del Café, 2006; Mora, 2003, pp. 1-8), sin dejar de apuntar las dificultades derivadas de los malos precios de las décadas de 1980 y de 1990 (Castro y Guido, 2006).

De cara a lo mencionado, surge una pregunta inevitable que asalta al lector, a saber, ¿qué papel jugaron los boyeros al interior de la economía regional? Para entender el fenómeno se recurrió a los datos que brindaron varios censos nacionales u otras fuentes oficiales del Estado costarricense. De esta forma, se reinterpretarían las transformaciones que hubo en la región de estudio, para desentrañar cómo se incrementó y de qué forma decrecería el oficio del boyeo en una zona rural de Costa Rica.

\section{UN ACERCAMIENTO AL BOYERO DESDE LOS DATOS OFICIALES}

De acuerdo con algunas estadísticas agropecuarias de los albores del siglo XX, en San Ramón se censaron 1.951 bueyes para el bienio de 1909-1910 y cuatro años más tarde se contabilizaron 1.709 (Castro y Willink, 1989, p. 65). A partir de una tabla numerada como trece, la historiadora Silvia Castro junto al antropólogo Frank Willink reconstruyeron una parte del oficio con base en la categoría 
denominada como ocupaciones en fincas de café, donde San Ramón registró 66 boyeros y Palmares 24 durante el año 1935, lo que contrastó con tres y un chóferes de camiones, respectivamente, en los cantones mencionados.

Un decreto del Congreso Constitucional de 1934 habilitaba a la Junta Nacional de Carreteras para que construyera un acceso entre: “...San Ramón y Palmares con la carretera central de la provincia de Alajuela" (Archivo Nacional de Costa Rica, 1934). Una cuestión que casi una década y media antes fue discutida en la Municipalidad de San Ramón, cuando se expuso la necesidad de una ruta que acoplara a San Ramón, Palmares y Naranjo con la ciudad de Alajuela (Archivo Municipal San Ramón, 1920, p. 224). Dos décadas atrás, La Gaceta había anunciado la construcción del camino carretero hacia Río Grande, de modo que la importancia económica de la ruta era notoria $(1900$, p. 25). Con lo referido, se pueden observar las distintas estrategias y el desvelo que los grupos de poder emplearon para interconectar una región específica con una ciudad como Alajuela, que se articulaba con Heredia y, por supuesto, con la capital. En dicho escenario, una observación de Mario Samper contribuye a inferir un componente de las intenciones de los grupos de poder, es decir: "En la medida en que mejora la red de transporte se facilita, precisamente, el proceso de concentración agroindustrial... La red vial y la red ferroviaria cumplen, en parte, esa función" (1995, p. 204).

En el Censo Agropecuario de 1950, se pudo apreciar que la cantidad de animales en San Ramón era ligeramente parecida a la de 1914, a saber, 1.763 bueyes además de 835 carretas. El dato censal refiere a medios de transporte empleados en fincas ramonenses para ese año, lo que representaba un 52\%, mientras un $2 \%$ era referido a camiones, pues solo se detallaron 31 (Castro y Willink, 1989, p. 63) a lo largo y ancho de las extensiones empleadas para actividades pecuarias, es decir, unas 21.221 hectáreas (Dirección General de Estadística y Censos, 1950). En el cantón de Valverde Vega solo se contabilizaron 280 bueyes y estuvo valorado como el más bajo de la provincia de Alajuela (Dirección General de Estadística y Censos, 1950, p. 92). Se reitera que desde los años cuarenta la carretera Panamericana era una vía importante que atravesaba los cantones en cuestión e implantó un cambio agroeconómico significativo con un impacto en cuanto a los tipos de transporte y a la tracción animal utilizada (Ministerio de Obras Públicas y Transportes, 1984).

En el Censo Agropecuario de 1984 se señalaba que en la provincia de Alajuela había 4.425 bueyes. En un desglose por cantón, San Ramón arrojó un total de 728 y Palmares con apenas 38 kilómetros cuadrados contabilizó 14 bueyes (Dirección General de Estadística y Censos, 1987, p. 121), equivalentes a siete yuntas, lo que evidenciaba una escasa utilidad en una población de 17.815 habitantes. Al menos, 
siete boyeros fueron los registrados por los censistas. Sin embargo, Atenas apareció con 203 animales en el mismo año, cuando su población era de 15.011 personas. Como componente suplementario del recuento, un dato del Censo de Población de 1984 indicaba que en el país había una población de 2.416.809 habitantes y de estos, 427.962 vivían en la geografía alajuelense con poco más de 165.000 moradores en los ocho cantones al noroccidente del Valle Central (Hernández, 1985, pp. 153-156).

\section{ENTRE EL SÍMBOLO Y UNA EXPLICACIÓN HISTÓRICA}

En la década de 1980, denominada esta como "perdida” por los descalabros macroeconómicos internacionales, el impacto negativo en la sociedad costarricense se hizo palpable y en ese período una sugestiva declaratoria oficial tuvo lugar en torno a la carreta de bueyes como: "Símbolo nacional del trabajo". Propiamente, en 1988 se emitió la designación que patentizaba la inactividad del medio de transporte decimonónico que, al menos, en el Valle Central era percibido más abiertamente, quizás no tanto en Guanacaste o en la Zona Norte. La declaratoria gubernamental plasmada en el Decreto Ejecutivo No. 18197-C del 22 de marzo de ese año sostuvo una argumentación con un sentido histórico, sin dejar de lado el económico, que rezaba así: “...fue el principal instrumento de trabajo que en el siglo XIX y principios del presente, permitió el acarreo y la exportación del café base del impulso económico de Costa Rica” (Colección de Leyes y Decretos de Costa Rica, 1988, p. 28 D).

\section{UN DESAJUSTE SOCIAL DE LA REGIÓN}

Pese a lo anterior, la exaltación de ese rústico medio de transporte como símbolo "nacional" guardaría sus paradojas, que de una u otra manera saltaron a la vista al noroccidente del Valle Central. Por ejemplo, el cantón de Valverde Vega, formado en 1949 y mejor conocido como Sarchí, fue parte de los desajustes sociales de la región. Sin olvidar que el cantón había florecido bajo el principio turístico de "cuna de la artesanía nacional", lo que aglutinaba una posibilidad económica por la decoración de las carretas con técnicas y estilos depurados que no debe desestimarse (Alfaro, 1995, pp. 49-54). No obstante, la comunidad tuvo una gama de limitaciones y la artesanía como tal era una forma de subsistencia, sin resolver otros problemas sociales, entre aspectos como las migraciones hacia los Estados Unidos (Pérez, 1996; Caamaño, 2011). En el Decimosegundo Informe Estado de la Nación de 2005, Sarchí apareció como el cantón con más alta tasa de 
incidencia de deserción colegial, con un 18,1\%, en contraste con Atenas que tan solo tuvo un 4,9\%, la tasa más baja de la provincia de Alajuela (Programa Estado de la Nación, 2005, p. 63). Estos elementos brindarían un criterio en torno al ciclo de empobrecimiento de un cantón denominado como "turístico", al calor de los espejismos que la actividad ha tenido en el país.

\section{ENTRE LA REFLEXIÓN Y LOS COMENTARIOS FINALES}

En esta investigación, se aprecia que desde la década de 1970 varios aspectos como la inauguración de la carretera Bernardo Soto, la bonanza coyuntural en el precio del café y una masificación del transporte automotor, entre otras razones, crearon las condiciones que fueron suplantando la tracción animal. Aunque el proceso fue paulatino, produjo un declive en el oficio del boyeo, que en la década de 1990 era casi extinto con ciertas excepciones de boyeros empobrecidos, renuentes a dejar sus faenas y sin representar un gremio importante dentro de la fuerza laboral.

Tampoco se debe omitir que las diversas compañías de automotores, entre ellas Internacional Harvester, Magirus Deutz, Willis y su jeep militar de la Segunda Guerra Mundial o de Vietnam, los chapulines y el Land Rover, desplazaron poco a poco la tosca carreta. La compañía japonesa Toyota hizo su agosto en Costa Rica con el denominado pick up y ofreció una alternativa al transporte, dado que cada vez hubo más recursos monetarios con las bonanzas del café. También, se podría adicionar que la economía requirió de condiciones mecánicas más sofisticadas, desmarcándola de los tradicionales transportes de fuerza animal.

A raíz de las características convencionales del boyeo, esta actividad poseyó algunas particularidades, sin desestimar otros sectores ocupacionales; entre tanto, el trabajo a destajo se convirtió en una limitación importante en materia de pensiones. Por consiguiente, no era ajeno al mundo rural el observar las desgastadas yuntas detrás de los viejos boyeros, arrastrados hacia un lodazal de limitaciones económicas y probablemente con una precaria salud personal, que les guardaría de parafrasear varias líneas del Romance de Marchena, en razón de sus contenidos. El modus vivendi del boyero pondría en entredicho el regocijo que el poema intenta reflejar:

$\mathrm{Al}$ emprender el retorno

se advierten que van de fiesta;

aligeradas de carga,

dieron fin a la faena. 
En la actualidad, un elemento llamativo en el noroccidente del Valle Central y de otras regiones del país se centra en los monumentos conmemorativos que intuyen una parcela del pasado, pero con un matiz romántico. Por ejemplo, en los jardines del templo parroquial de San Ramón Nonato se instaló una escultura que representa al boyero tirando de su carreta - cuesta arriba-, elaborada por el escultor Edgar Zúñiga por encargo de una comisión de boyeros ramonenses y con el patrocinio económico de algunos empresarios locales. En abril de 2003, en el distrito de Los Ángeles de Atenas, se inauguró un monumento del artista español Manuel Torrecillas, quien rubricó bajo el alias ibérico de Manolo. El proyecto y su inversión estuvieron a cargo de la Asociación Nacional de Boyeros, la Cámara de Turismo y la Asociación de Desarrollo Integral de Los Ángeles. El emplazamiento de la obra no fue improvisado, pues se hizo a la vera de la antigua ruta entre San José y Puntarenas. En 2006, la Cámara de Comercio de Sarchí ubicó en el parque central una voluminosa carreta fabricada en el taller de Eloy Alfaro, luego se instaló un yugo de varias toneladas - pero sin bueyes - que, aseguran los vecinos, serían los más grandes del planeta Tierra.

Para finalizar, tal como se aludió al comienzo de este artículo, en Costa Rica se establecieron agendas locales para agasajar a los boyeros, entre placas y monumentos que usualmente cierran con desfiles en una amplia gama de comunidades. En Guanacaste, Alajuela, Heredia, Cartago y San José no se les resta importancia al homenaje y a la celebración de este sujeto histórico. A esta tarea se sumaría Correos de Costa Rica (Díaz, 2006, 21 A), emitiendo un matasello con una silueta de una yunta, pero sin el elemento humano, bajo la leyenda: "24 de noviembre, 2006. X Entrada de los santos $y$ desfile de boyeros a San Josê'. Mejor aún, en noviembre de 2005, la UNESCO hizo una declaración formal en torno al oficio del boyeo y de la carreta que expresaba lo siguiente: Obra maestra del patrimonio oral e inmaterial de la Humanidad ${ }^{8}$, según una petitoria del Ministerio de Cultura, Juventud y Deportes costarricense.

\section{CITAS Y NOTAS}

1. Mario González Feo publicó en 1967 un cuento bajo el mismo título.

2. En este artículo se cita la tercera edición de 1972, a cargo de EDUCA.

3. (Junta Edificadora de Zaragoza, 1921; Parroquia de La Merced, 1925; Archivo de la Curia Metropolitana, 1906). Entrevistas llevadas a cabo por Javier Rodríguez a Fernández (1994) y Bolaños (1994). 
4. (Castro y Willlink, 1989; Torres, 1989; Abarca, 1999; Badilla y Solórzano, 2010).

5. (Rodríguez, 2007, pp. 141-150). Una fractura importante en la región estuvo centrada en el interés de un grupo de ramonenses, quienes pretendieron crear una provincia a la que denominarían La Paz, un proceso que requirió de varios plebiscitos. En 1916, se celebró el último en beneficio del ayuntamiento de Alajuela en contubernio con varios dirigentes de Palmares, manipulados por el padre Gómez y al amparo de varios ediles del municipio. El Parque Palmares en la ciudad de Alajuela es un vástago de esa lucha regional que dividió a las comunidades por décadas, tal como lo afirman Yamileth González y María Pérez (1995).

6. Actualmente, funciona como una especie de Casa de la cultura, aunque denominada bajo el rango de Museo Ferroviario y entendido como un logro de la organización de sus propios pobladores, quienes lidiaron contra la adversidad, dado que el inmueble de la década de 1930 estuvo ocupado ilegalmente, tiempo después de paralizarse el servicio del tren.

7. (Rodríguez, 2007, pp. 141-143). En 1911, los vecinos de Candelaria y Santiago optaron por anexarse a Palmares, lo que fragmentó una parte del territorio de Atenas.

8. Ministerio de Cultura Juventud y Deportes del gobierno de Costa Rica y la UNESCO de 2005, expediente de la candidatura: Obra maestra oral e intangible de la humanidad.

\section{REFERENCIAS}

Abarca, C. (1999). Siglo y medio de identidades palmareñas. Costa Rica: CAAV.

Abarca, C. (2011). Historia de San Carlos: 1890-1950. Costa Rica: Z Servicios Gráficos S.A.

Alfaro, A. (1995). La carreta: un elemento significativo de la cultura costarricense. Herencia, 7 y 8 (1-2), 49-54.

Archivo Nacional de Costa Rica. (1934). Serie Congreso, expediente 17.097. Costa Rica: Archivo Nacional de Costa Rica.

Archivo Municipal de San Ramón. (1920). Carretera San Ramón-Alajuela, f. 224. Costa Rica: Archivo Municipal de San Ramón.

Archivo Nacional de Costa Rica. (1855). Serie Gobernación, expediente 28500, folios 1-4v. Costa Rica: Archivo Nacional de Costa Rica. 
Archivo Nacional de Costa Rica. (1934). Serie Congreso, expediente 17097. Costa Rica: Archivo Nacional de Costa Rica.

Anuario General de Costa Rica. (1934). Costa Rica: Imprenta Borrasé.

Archivo de la Curia Metropolitana. (1906). Fondos Antiguos, caja 456, folio 38. Costa Rica: Archivo de la Curia Metropolitana.

Badilla, M. y Solórzano, W. (2010). De territorio a región. Bases estructurales para la creación de las regiones Occidente y Norte de Costa Rica: 1821-1955. Costa Rica: Sociedad Editora Alquimia 2000.

Bolaños, S. (agosto de 1994). Entrevista personal. (J. Rodríguez, Entrevistador).

Caamaño, C. (2011). Entre “arriba” y “abajo”. La experiencia transnacional de la migración de costarricenses hacia los Estados Unidos. Costa Rica: EUCR.

Castro, S. y Guido, F. (2006). Crisis cafetalera y condiciones de vida de pequeños y medianos productores de café en San Ramón de Alajuela. Costa Rica: Sede de Occidente, Universidad de Costa Rica.

Castro, S. y Willink, F. (1989). San Ramón: economía y sociedad 1900-1948. Costa Rica: Sede de Occidente, Universidad de Costa Rica.

Chang, G. (2009). Costarriqueñismos en el léxico del boyeo. Káñina, 23 (1), 107-117.

Colección de Leyes y Decretos de Costa Rica. (1988). Decreto $N^{\circ} 18197-C$. Costa Rica: Colección de Leyes y Decretos de Costa Rica.

Del Olmo, J. (1929). Naranjo y su iglesia. Costa Rica: Imprenta Lehmann.

Dirección General de Estadística y Censos. (1950). Censo Agropecuario. Costa Rica: MEH- DGEC.

Dirección General de Estadística y Censos. (1973). Censo Nacional de Población. Costa Rica: MEH- DGEC.

Dirección General de Estadística y Censos. (1984). Censo Agropecuario. Costa Rica: MEH- DGEC.

Dirección General de Estadística y Censos. (1984). Censo Nacional de Población. Costa Rica: MEH- DGEC.

Dirección General de Estadística y Censos. (1987). Censo Agropecuario. Costa Rica: MEH- DGEC. 
Dirección General de Estadística y Censos. (1987). Censo Nacional de Población. Costa Rica: MEH- DGEC.

Díaz, D. (2006, noviembre 25). Boyeros son homenajeados con exposición y matasello. La Nación. p. 21

Díaz, D. (2006, noviembre 27). San José llegó a la capital entre boyeros, fiesta y bendiciones. La Nación.p. 24 A.

Dobles, C., Murillo, C. y Chang, G. (2008). Boyeros, bueyes y carretas. Por la senda del patrimonio intangible. San José: EUCR, Colección Identidad Cultural.

Fernández, R. (1972). Costa Rica en el siglo XIX. Antología de viajeros. (3ra. Ed.). Costa Rica: EDUCA.

Fernández, A. (agosto de 1994). Entrevista personal. (J. Rodríguez, Entrevistador).

González, Y. y Pérez, M. (1995). Un proceso de colonización tardía y dispersa. El Valle de los Palmares. Anuario de Estudios Centroamericanos, 21(1-2), 141-164.

Hall, C. (1991). El café y el desarrollo histórico-geográfico de Costa Rica. Costa Rica: Editorial Costa Rica.

Hernández, H. (1985). Costa Rica. Evolución territorial y principales censos de población: 15021984. Costa Rica: EUNED.

Instituto Costarricense del Café. (2006). Producción cafetalera en Costa Rica. Costa Rica: Instituto Costarricense del Café.

Junta Edificadora de Zaragoza. (1921). Libro de actas. Costa Rica: Junta Edificadora de Zaragoza.

La Gaceta. (7 de julio de 1900). Diario Oficial. La Gaceta, p. 25.

Láscaris, C. y Malavassi, G. (1975). La carreta costarricense. Costa Rica: Departamento de Publicaciones del Ministerio de Cultura, Juventud y Deportes.

Marchena, J. (1941). Alas en fuga. Costa Rica: Imprenta Nacional.

Meagher, T. F. (1972). De Punta Arenas a San José. En R. Fernández. (Ed.). Costa Rica en el siglo XIX. Antología de viajeros. (3ra. Ed.). (pp. 333-448). Costa Rica: EDUCA. 
Ministerio de Obras Públicas y Transportes. (1984). Reseña histórica de los transportes en Costa Rica. Costa Rica: Gobierno de Costa Rica.

Mora, J. A. (2003). Cafés del Valle Central Occidental: sinónimo de cafés de alta calidad. Costa Rica: Instituto Costarricense del Café.

Murillo, C. (1995). Identidades de hierro y humo: la construcción del ferrocarril al Atlántico 18701890. Costa Rica: Editorial Porvenir.

Parroquia de La Merced. (1921). Carta del Padre Mardoqueo Arce al obispo de Alajuela. Costa Rica: Archivo Parroquial de Palmares.

Pérez, H. y Baires, Y. (1987). Crecimiento y crisis de las economías centroamericanas: 1950-1980. Anuario de Estudios Centroamericanos, 13 (2), 63-92.

Pérez, J. P. (1996). Neoinformalidad dinámica: El caso de la artesanía de Sarchí, Costa Rica. En Neoinformalidad en Centroamérica. (pp. 83-110). Costa Rica: FLACSO-Costa Rica.

Programa Estado de la Nación. (2005). Resumen. Costa Rica: Programa Estado de la Nación.

Rodríguez, J. (1997). Los ejes de la carreta. Rumbo, 644 (1), 44.

Rodríguez, J. (2007). Un legado histórico-social y arquitectónico en el cantón de Palmares. Reflexiones, 86 (1), 141-150.

Rodríguez, J. (2008). Visiones de la pobreza en Costa Rica. En A. Santana. (Coord.). Costa Rica en los inicios del siglo XXI. (pp. 203-225). México: Centro de Investigaciones sobre América Latina y el Caribe, UNAM.

Rodríguez, J. (2012). Las políticas sociales en materia de pobreza y su institucionalización en Costa Rica: 1970-1978. Una aproximación histórica al Instituto Mixto de Ayuda Social (IMAS). Manuscrito inédito, Centro de Investigaciones Históricas de América Central, Universidad de Costa Rica, San José, Costa Rica.

Rojas, M. y Ovares, F. (1995). 100 años de literatura costarricense. Costa Rica: Ediciones Farben, Grupo Editorial Norma.

Samper, M. (1991). El trabajo en la sociedad rural costarricense: 1840-1940. Costa Rica: EUNED.

Samper, M. (1995). Crecimiento agroexportador y transformación social en Centroamérica: 18501930. En M. Vannini. (Ed.). Encuentros con la historia. (pp. 177-210). Nicaragua: Instituto 
de Historia de Nicaragua.

Samper, M. (1998). Producción cafetalera y poder político en Centroamérica. Costa Rica: EDUCA.

Sandí, J. (2011). La participación de la Iglesia católica en el control del espacio en medio de la creación de un país llamado Costa Rica: 1850-1920. Revista de Historia, (63 y 64), 53-99.

Sanou, O. (2001). Arquitectura e historia de Costa Rica. Templos parroquiales en el Valle Central: Grecia, San Ramón y Palmares. Costa Rica: EUCR, Comisión Nacional de Conmemoraciones Históricas.

San Ramón se lució en festejos patronales. Entre Cantones, 20 (2), 16-19.

Sociedad Económica de Guatemala. (18 de febrero de 1848). La revista. No. 58. Guatemala: Sociedad Económica de Guatemala.

Torres, J. L. (1989). Naranjo y su historia: 1835-1988. Costa Rica: Comisión Nacional de Conmemoraciones Históricas.

Ulloa, H. (1997). El ferrocarril costarricense al Pacífico. Construcción e incidencias: 1895-1932. Costa Rica: Editorial Costa Rica.

Zeledón, F. (2010). La construcción de la carretera Inter Americana en Guanacaste. Estado, región y medios de comunicación: 1943-1970. En: R. Núñez y J. J. Marín. (Eds.). Historia de la (Re) construcción de una región 1850-2007. (pp. 103-135). Costa Rica: Alma Mater.

\section{ACERCA DEL AUTOR}

Javier Rodríguez Sancho: Historiador. Sección de Historia y Geografía. Sede de Occidente. Universidad de Costa Rica. Correo electrónico: Javier.rodriguezsancho@ucr.ac.cr 